EESTI NSV TEADUSTE AKADEEMIA TOIMETISED. X KOIDE

FOOSIKALIS-MATEMAATILISTE JA TEHNILISTE TEADUSTE SEERIA. 1961, NR. 3

ИЗВЕСТИЯ АКАДЕМИИ НАУК ЭСТОНСКОИ ССР. ТОМ Х

СЕРИЯ ФИЗИКО-МАТЕМАТИЧЕСКИХ И ТЕХНИЧЕСКИХ НАУК. 1961, № 3

\title{
О ТЕМПЕРАТУРОПРОВОДНОСТИ СЛАНЦА-КУКЕРСИТА В ПРОЦЕССЕ ЕГО НАГРЕВАНИЯ И ТЕРМИЧЕСКОГО РАЗЛОЖЕНИЯ *
}

\author{
Р. ВАЛДЕК, Н. Л. ЛУЦКОВСКАЯ, \\ кандидаты технических наук
}

ю. ЭИЗЕН

При проведении теоретических и практических расчетов процессов термической переработки горючих сланцев необходимо знать и термические характеристики последних. Однако теоретические основы термической переработки горючих сланцев, особенно в процессе их нагревания, изучены еще неполностью.

При нагревании горючих сланцев в них происходят различные химические и фнзическне процессы, резко изменяющие свойства и массу исходного вещества и тем самым затрудняющие исследование их теплофизических свойств. Кроме того, пласты сланца-кукерсита значительно отличаются друг от друга по своим свойствам и составу, включая конкреции разной величины и в разных количествах.

Большннство имеющихся в настоящее время данных о коэффициенте температуропроводности сланца-кукерсита получено при низких температурах как для проб исходного сланца, так и для проб сланца, предварительно обработанных при различных температурах $\left[{ }^{1-4}\right]$. Исключение составляют исследования К. Куйва, проведенные при высоких температурах [5, б].

В настоящей работе для определения коэффициента. температуропроводности горючего сланца и его кокса применялся метод нагревания тела в среде, температура которой изменяется с постоянной скоростью (линейно). На основании теоретических н экспериментальных исследований $\left[{ }^{7}\right]$ известно, что начиная с определенного момента температура любой точки тела становится линейной функцией времени, а распределение температуры в одномерных задачах описывается законом параболы (квазнстацнонарный режим).

В описываемой работе исследуемый образец брался в форме так называемого неограниченного цилиндра, для которого коэффициент температуропроводности $a$ рассчитывался по формуле [7]

$$
a=\frac{b R^{2}}{\Gamma\left(t_{\mathrm{n}}-t_{\mathrm{u}}\right)},
$$

где $b$ - скорость нагревания среды; $R$ - радиус цилиндра; $\Gamma$ - постоянное число (для неограниченного цилиндра $\Gamma=4) ; t_{n}-$ темпера-

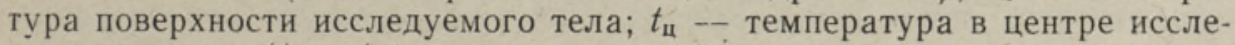
дуемого тела; $\left(t_{n}-t_{\text {u }}\right)$ - разность температур поверхности и центра исследуемого тела.

* В экспериментальной части работы принимал участие инженер А. Верк. 
Исследование проводилось в трубчатой печи с открытой обмоткой (из ленты сплава № 2). Для осуेшествления линейного подъема температуры печи с требуемой скоростью был создан специальный программный регулятор температуры, основой которого служит пирометрический регулирующий милливольтметр.

Для измерения температур использовался пирометр Курнакова и самопишущий милливольтметр. Измерение скоростей нагревания массивного металлического блока в печи и поверхности исследуемых целиков показало, что они во время всего процесса нагревания практически равны. Әто подтверждает соблюдение квазистационарного режима в условиях постановки опытов.

Исследования проводились на цилиндрических целиках, высверленных перпендикулярно слоистости из больших кусков сланца. Длина полученных цилиндров колебалась в пределах $80-100$ мм при диаметре 34,4 мм. По центральной оси цилиндров высверливалось отверстие глубиной $40-50$ мм и диаметром 5 мм.

Сланцевый целик помещался в кварцевый цилиндр, который закрывался резиновой пробкой с пропущенными через нее кварцевым чехлом для термопары (измеряющей температуру поверхности сланцевого целика) и кварцевой трубкой, служащей для отвода парогазовой смеси и ввода кварцевого чехла (для термопары, измеряющей температуру центра сланцевого целика). Конец трубки, обращенный к образцу сланца, имел расширение диаметром на 1 -2 мм меньше внутренного диаметра кварцевого цилиндра. Пространство между расширением трубки и резиновой пробкой цилиндра заполнялось асбестовым волокном. Заполненный таким образом кварцевый цилиндр вставлялся в канал массивного металлического блока (из жаростойкой стали), помещенного в трубчатую

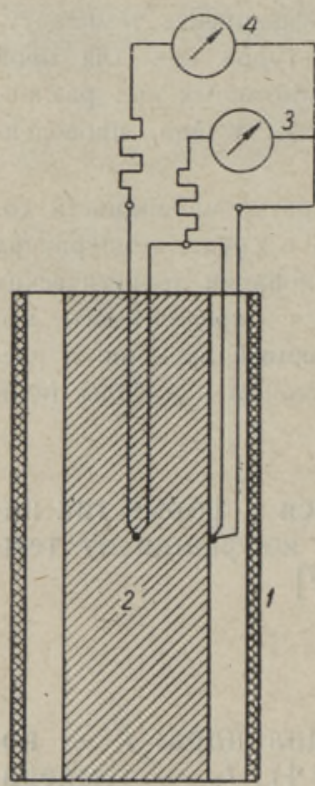
печь. Часть цилиндра, находящаяся вне печи, экранировалась от сильно нагретого блока асбестом и специальным металлическим устройством с проточной водой. Все зазоры между стенками цилиндра и выводным отверстием печи тщательно заделывались асбестом для избежания конвекционных токов в печном пространстве.

Трубка, служащая для отвода парогазовой сме си, соединялась с градуированным приемником смолы и далее через обратный холодильник с газометром. Вся система проверялась на герметичность. В кварцевые чехлы, помещенные на поверхности и в центре сланцевого цилиндра, вставлялись горячие спаи комбинированной термопары, подключенной к высокочувствительным зеркальным гальванометрам пирометра Курнакова. Схема подключения термопар прнведена на фиг. 1.

Фиг. 1. Схема расположения горячих спаев комбинированной термопары и подключения ее к высокочувствительным гальванометрам 3 и 4: 1 - стенки кварцевого цилиндра; 2 - сланцевый целик.

Во всех опытах нагревание сланцевых (и коксовых) целиков проводилось со скоростью 3 град/мин. Градуировка термопары, присоединенной к гальванометру простой записи, производилась на основе солей; градуировка термопары, присоединенной к гальванометру диф- 
ференциальной записи, производилась по разности температур дистиллированной воды в двух сосудах Дюара. На основании полученных данных составлялись рабочие градуировочные таблицы, с помощью которых расшифровывались полученные на термограммах температура поверхности исследуемого образца и разность температур между его поверхностью и центром.

Опыты производились с цилиндрическими образцами, , спрессованными из сланцевой пыли в специальной прессформе, с целиками, высверленными из пластов A, C и D сланца-кукерсита, и из кусков диктионемового сланца месторождения Маарду.

Таблица 1

Состав исследованных целиков горючего сланца и полученных из них коксов

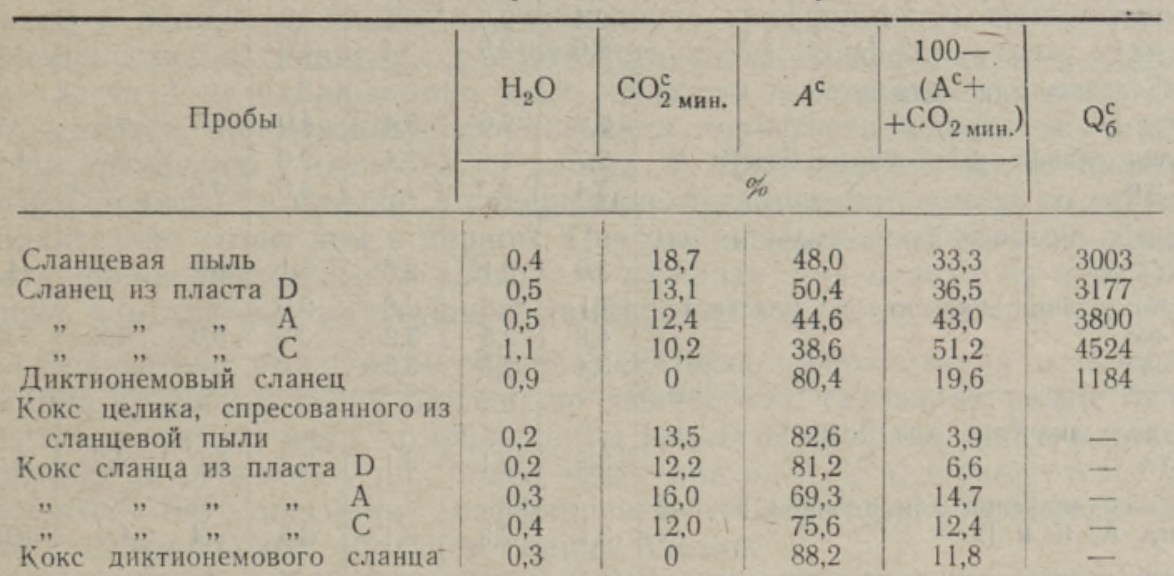

Параллельные опыты показали в общем одинаковые изменения разности температур между поверхностью и центром образца $\left(t_{n}-t_{u}\right)$ по мере увеличения температуры поверхности последнего $\left(t_{\mathrm{n}}\right)$. Только в области интенсивного изменения органического вещества (при 350-$500^{\circ}$ ) наблюдались резкие колебания этого показателя. В табл. 1 и 2 приведены данные, характеризующие целики исследованных горючих сланцев.

Таблица 2

Физические свойства исследованных целиков горючих сланцев

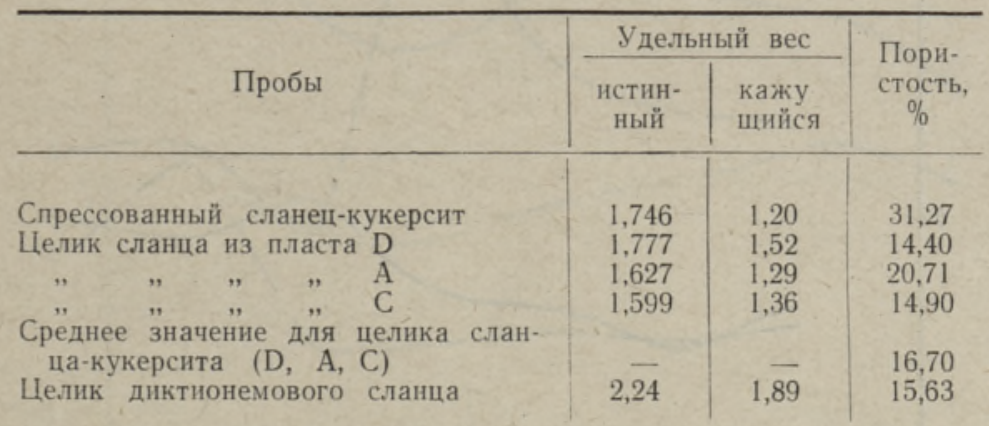

Результаты изучения изменения коэффициента температуропроводности целиков горючих сланцев в процессе их нагревания с эвакуацией летучих на холодную сторону представлены в табл. 3.

Анализируя полученные данные и сопоставляя их с данными табл. 1 и 2 , можно сделать заключение, что коэффициент температуропровод- 
Таблица 3

Зависимость коэффициента температуропроводности $\left(a \cdot 10^{4} \mathrm{~m}^{2} /\right.$ час) целиков горючего сланца от температуры образца

\begin{tabular}{|c|c|c|c|c|c|c|c|}
\hline \multirow{2}{*}{ Пробы } & \multicolumn{7}{|c|}{ Температура поверхности образща, ${ }^{\circ} \mathrm{C}$} \\
\hline & 100 & 200 & 300 & 400 & 500 & 600 & 700 \\
\hline $\begin{array}{l}\text { Целик, спрессованный из пыли сланца- } \\
\text { кукерсита } \\
\text { То же }\end{array}$ & $\begin{array}{l}3,1 \\
2,6\end{array}$ & $\begin{array}{l}2,0 \\
2,7\end{array}$ & $\begin{array}{l}2,1 \\
3,3\end{array}$ & 2,4 & 2,3 & $\begin{array}{l}2,8 \\
9,6\end{array}$ & $\begin{array}{l}2,4 \\
6,2\end{array}$ \\
\hline $\begin{array}{l}\text { Среднее значение } \\
\text { Целик сланца-кукерсита из пласта D } \\
\text { То же } \\
\text { То же }\end{array}$ & $\begin{array}{l}2,6 \\
2,4\end{array}$ & $\begin{array}{l}2,8 \\
2,5\end{array}$ & $\begin{array}{l}2,7 \\
3,5 \\
3,6 \\
3,1\end{array}$ & $\begin{array}{l}4,0 \\
3,8\end{array}$ & $\begin{array}{l}2,3 \\
6,6 \\
- \\
-\end{array}$ & $\begin{array}{l}6,2 \\
6,0 \\
- \\
-\end{array}$ & $\begin{array}{l}4,3 \\
- \\
- \\
\end{array}$ \\
\hline $\begin{array}{l}\text { Среднее значение для целиков из пла- } \\
\text { ста D } \\
\text { Целик сланца-кукерсита из пласта А } \\
\text { То же }\end{array}$ & $\begin{array}{l}2,6 \\
2,7\end{array}$ & & $\begin{array}{l}3,4 \\
2,4 \\
2,6\end{array}$ & $\begin{array}{l}4,0 \\
2,6\end{array}$ & $\frac{6,6}{4,5}$ & $\begin{array}{l}6,0 \\
3,6\end{array}$ & $\overline{4,4}$ \\
\hline $\begin{array}{l}\text { Среднее значение для целиков из пла- } \\
\text { ста А } \\
\text { Целик сланца-кукерсита из пласта С } \\
\text { То же } \\
\text { То же } \\
\end{array}$ & $\begin{array}{l}3,0 \\
3,1 \\
4,8 \\
3,4\end{array}$ & $\begin{array}{l}2,1 \\
1,6 \\
2,5 \\
2,3\end{array}$ & $\begin{array}{l}2,5 \\
2,8 \\
3,2 \\
3,3\end{array}$ & $\begin{array}{l}3,1 \\
2,6 \\
3,3 \\
3,6\end{array}$ & $\frac{4,5}{5,0}$ & $\frac{3,6}{\overline{4,2}}$ & $\frac{4,4}{5, \overline{5}}$ \\
\hline $\begin{array}{l}\text { Среднее значение для целиков из пла- } \\
\text { ста С }\end{array}$ & 3,8 & 2,1 & 3,1 & 3,2 & 5,0 & 4,2 & 5,5 \\
\hline $\begin{array}{l}\text { Среднее значение для целиков из пла- } \\
\text { ста А, С и D }\end{array}$ & 3,1 & 2,3 & 3,1 & 3,5 & 5,4 & 4,6 & 5,0 \\
\hline $\begin{array}{l}\text { Целик диктионемового сланца } \\
\text { То же }\end{array}$ & $\begin{array}{l}8,1 \\
5,9\end{array}$ & $\begin{array}{l}8 \\
5\end{array}$ & $\begin{array}{l}9,1 \\
7,2\end{array}$ & $\begin{array}{l}10,5 \\
13,4\end{array}$ & $\begin{array}{l}6,2 \\
3,0\end{array}$ & $\begin{array}{l}8,0 \\
5,1\end{array}$ & 二. \\
\hline $\begin{array}{l}\text { Среднее значение для целиков ди } \\
\text { немового сланца }\end{array}$ & 7,0 & 7,1 & 8,2 & 11,9 & 4,6 & 6,6 & - \\
\hline
\end{tabular}

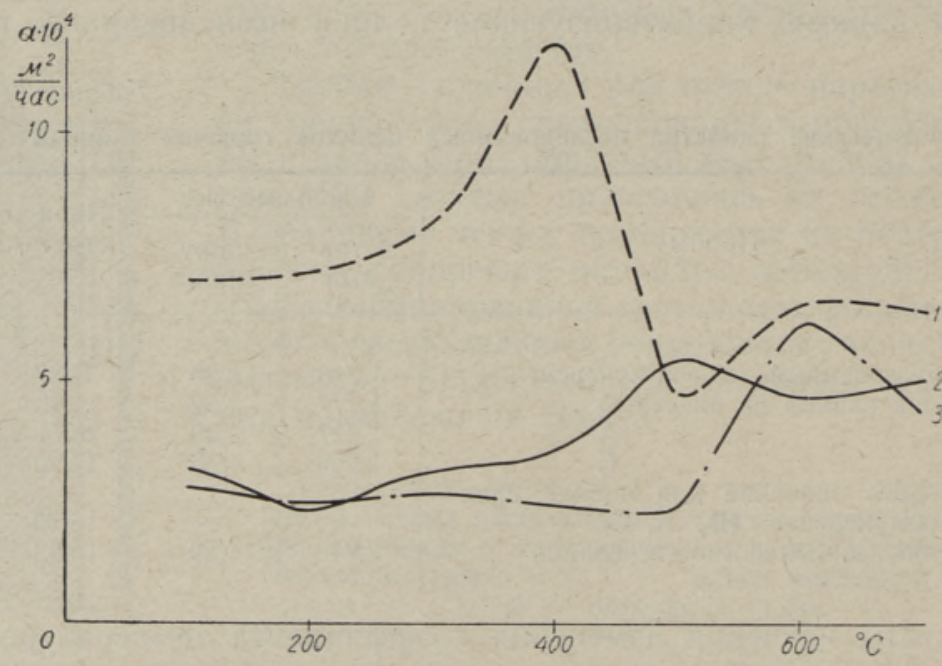

Фиг. 2. Изменение коэффициента температуропроводности с повышением температуры для: 1 - целика диктионемового сланца; 2 - целика сланца-кукерсита; 3 - прессованного сланцакукерсита. 
ности горючих сланцев зависит как от их химического состава, так и физических свойств. Так, для образцов спрессованного сланца и целика сланца-кукерсита из пласта D, у которых различия в химическом составе невелики, пористость отличается более чем в 2 раза (31 и 14\%), и коэффициенты температуропроводности для соответствующих температур у образца спрессованного сланца ниже, чем у целика сланцакукерсита из пласта D. Здесь, несомненно, сказывается влияние пористости. С увеличением содержания органической массы в исследуемых целиках при переходе от целиков из пласта D к целикам из пласта А коэффициент температуропроводности уменьшается, как и следовало ожидать, тем более, что пористость второго целика больше пористости первого. Но при дальнейшем увеличении содержания органической массы в целике из пласта С уменьшение коэффициента температуропроводности по сравнению с соответствующим коэффициентом целика из пласта А не наблюдается, даже наоборот, - заметен его рост. Это объясняется, по-видимому, уменьшением пористости целика из пласта C по сравнению с целиком из пласта А. Для целиков же из пластов D и C пористости близки, а содержание органической массы во втором значительно выше, чем в первом. Поэтому здесь и коэффициент температуропроводности, как и следовало ожидать, для целика из пласта С ниже, чем для соответствующих температур целика из пласта D.

Показатели пористости образца диктионемового сланца и целиков сланца-кукерсита очень близки, но химический состав их резко отличается, в связи с чем и коэффициенты температуропроводности в пределах $400^{\circ}$ отличаются у них более, чем в два раза. В интервале температур $500-700^{\circ}$ значения коэффициента температуропроводности для всех исследованных образцов сланца близки.

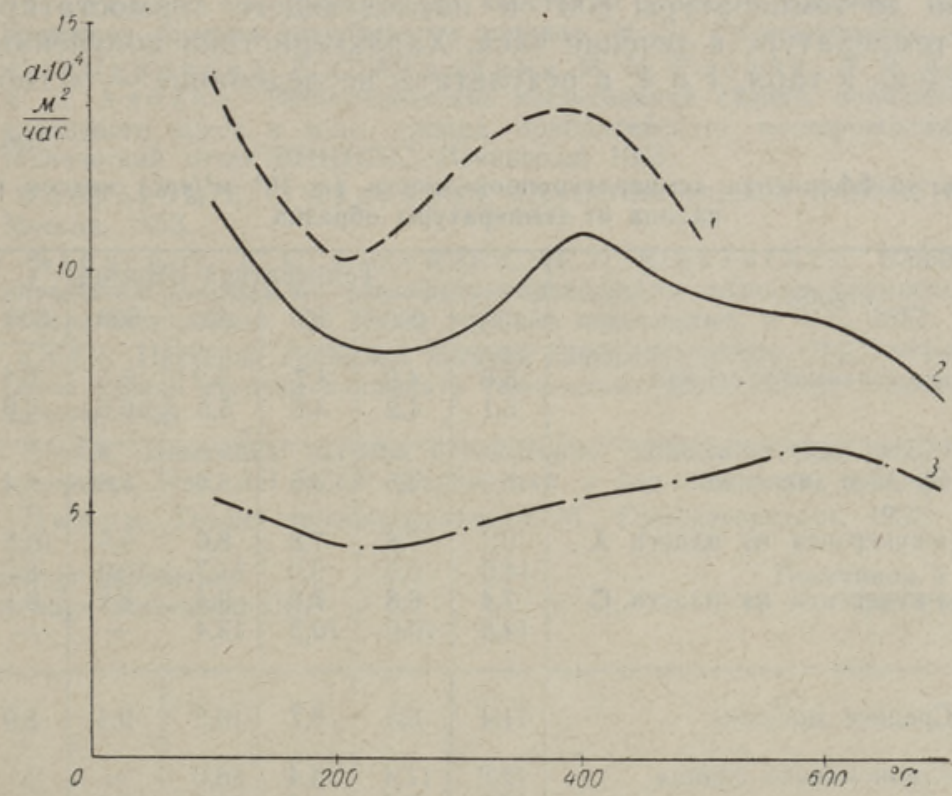

Фиг. 3. Изменение коэффициента температуропроводности с повышением температуры для коксов из: 1 - целика диктионемового сланца; 2 - целика сланца-кукерсита; 3 - прессованного сланца-кукерсита. 
Таблица 4

Физические свойства коксов горючих сланцев

\begin{tabular}{|c|c|c|c|}
\hline \multirow[b]{2}{*}{ Пробы } & \multicolumn{2}{|c|}{ Удельный вес } & \multirow{2}{*}{$\begin{array}{l}\text { Пори- } \\
\text { стость, \% }\end{array}$} \\
\hline & истинный & $\begin{array}{l}\text { кажу- } \\
\text { щийся }\end{array}$ & \\
\hline $\begin{array}{l}\text { Кокс спрессованного сланца- } \\
\text { кукерсита }\end{array}$ & 3,037 & 0,66 & 78,27 \\
\hline $\begin{array}{l}\text { Кокс сланца-кукерсита из пла- } \\
\text { ста А }\end{array}$ & 2,270 & 0,85 & 62,56 \\
\hline То же & 2,534 & 0,79 & 68,82 \\
\hline $\begin{array}{l}\text { Кокс сланца-кукерсита из пла- } \\
\text { ста С }\end{array}$ & 2,633 & 0,69 & 73,79 \\
\hline То же & 2,495 & 0,94 & 62,32 \\
\hline То же & 2,610 & 0,65 & 75,09 \\
\hline $\begin{array}{l}\text { Среднее значение для коксов } \\
\text { целиков сланца-кукерсита }\end{array}$ & - & - & 68,51 \\
\hline Кокс диктионемового сланца & 2,114 & 1,66 & 21,48 \\
\hline
\end{tabular}

Ввиду того, что после $350^{\circ}$ из образцов сланца начинается интенєивное газовыделение, которое влияет на температуропроводность образца, коэффициент температуропроводности в этих условиях следует рассматривать как $a_{9 ф}$, присущее образцу только в данных конкретных условиях.

В работе были также изучены коэффициенты температуропроводности коксов целиков сланца, полученных при нагревании со скоростью 3 град/мин до температуры $800^{\circ}$ и последующего термостатирования при этой температуре в течение часа. Характеристика полученных коксов приведена в табл. 1 и 4, а результаты исследования - в табл. 5.

Таблица 5

Зависимость коэффициента температуропроводности $\left(a \cdot 10^{4} \mathrm{~m}^{2} / 4 а с\right)$ коксов горючего сланца от температуры образца

\begin{tabular}{|c|c|c|c|c|c|c|c|}
\hline \multirow{2}{*}{ Пробы } & \multicolumn{7}{|c|}{ Температура образца, ${ }^{\circ} \mathrm{C}$} \\
\hline & 100 & 200 & 300 & 400 & 500 & 600 & 700 \\
\hline $\begin{array}{l}\text { Кокс из спрессованного сланца } \\
\text { То же }\end{array}$ & $\begin{array}{l}5,6 \\
5,1\end{array}$ & $\begin{array}{l}4,9 \\
4,2\end{array}$ & $\begin{array}{l}4,7 \\
4,6\end{array}$ & $\begin{array}{l}5,2 \\
5,5\end{array}$ & $\begin{array}{l}5,5 \\
6,0\end{array}$ & $\begin{array}{l}6,4 \\
6,3\end{array}$ & 5,3 \\
\hline Среднее значение & 5,3 & 4,5 & 4,6 & 5,3 & 5,8 & 6,4 & 5,4 \\
\hline $\begin{array}{l}\text { Кскс сланца-кукерсита из пласта А. } \\
\text { Tо же } \\
\text { Кокс сланца-кукерсита из пласта С } \\
\text { To же }\end{array}$ & $\begin{array}{r}9,1 \\
14,6 \\
7,4 \\
14,5\end{array}$ & $\begin{array}{r}7,6 \\
9,6 \\
6,8 \\
10,0\end{array}$ & $\begin{array}{r}7,8 \\
9,0 \\
7,8 \\
10,3\end{array}$ & $\begin{array}{r}8,6 \\
11,7 \\
9,4 \\
13,4\end{array}$ & $\begin{array}{r}9,5 \\
10,0 \\
8,8 \\
-\end{array}$ & $\begin{array}{r}10,5 \\
8,2 \\
8,1 \\
\end{array}$ & $\overline{-}$ \\
\hline Среднее значение & 11,4 & 8,5 & 8,7 & 10,8 & 9,4 & 8,9 & 7,3 \\
\hline $\begin{array}{l}\text { Кокс из диктионемового сланца } \\
\text { Tо же }\end{array}$ & $\begin{array}{l}12,2 \\
15,9\end{array}$ & $\begin{array}{r}11,4 \\
9,0\end{array}$ & $\begin{array}{r}14,4 \\
9,8\end{array}$ & $\begin{array}{l}16,0 \\
10,5\end{array}$ & $\frac{1}{10,6}$ & $\overline{-}$ & $\overline{-}$ \\
\hline Среднее значение & 14,0 & 10,2 & 12,1 & 13,3 & 10,6 & - & - \\
\hline
\end{tabular}


Изменение коэффициента температуропроводности с повышением температуры для различных образцов горючего сланца и его кокса изображено на кривых фиг. 2 и 3.

Из вышеизложенного следует, что при переходе от сланца к коксу величина коэффициента температуропроводности резко возрастает, особенно у образцов целиков сланца-кукерсита, более резко изменивших свой химический состав, чем диктионемовый сланец.

Пористость кокса диктионемового сланца меньше пористости кокса сланца-кукерсита более чем в 3 раза, а значения коэффициентов температуропроводности при соответствующих температурах имеют близкие величины. Здесь, по-видимому, различия в химическом составе и пористости оказывают на коэффициенты температуропроводности противоположное влияние и тем самым уравновешивают их.

Химический состав коксов, полученных из спрессованных образцов и из целиков пластов А и С, близок, но пористость первых на $10 \%$ выше, чем у вторых; соответствующие значения коэффициентов температуропроводности у коксов, полученных из спрессованңых образцов, почти в 2 раза ниже, чем у коксов, полученных из целиков пластов А и С.

На основании этих данных можно заключить, что коэффициент температуропроводности целиков горючих сланцев и их коксов с увеличением пористости уменьшается, но эта закономерность соблюдается лишь для образцов, имеющих близкий химический состав, так как последний очень сильно влияет на коэффициент температуропроводности.

\section{ЛИТЕРА Т У РА}

1. В. В. Помер анцев, Термические константы твердого топлива. Исследование процессов горения. натурального топлива, М.-Л., Госэнергоиздат, 1948.

2. Г. Н. Скрынников а, Е. С. Авдонин а, М. М. Голяянд, Л. Я. Ахмедова, А. 11. Алехин, Теплофизические исследования сланца, породных прослоек, сланцевого кокса и золы сланца прибалтийского месторождения, Научнотехнический отчет ВНИИПС, Ленинград, 1955.

3. И. Л. Ф а 6 р ер ов, Е. С. А в дон и н а, Научно-технический отчет ИГИ АН СССР, Москва, 1953.

4. И. Л. Фа бр еров, Е. С. Авдонин а, Н. П. Юрьевская, Влияние предварительного нагрева на температуропроводность целиков подмосковного угля и горючего сланца, Тр. Ин-та горючих нскопаемых, т. УП, 1957.

5. К. А. К у й в, Изучение динамики нагрева сланца-кукерсита, Диссертация на соискание ученой степени кандидата технических наук, Ин-тут химии АН ЭССР, Таллин, 1956.

6. К. А. К у й в, Динамика нагрева и некоторые теплофизические свойства сланцакукерсита, Изв. АН ЭССР. Серия техн. и физ.-мат. наук, т. V, № 4, 1956.

7. А. В. Л ыков, Теория теплопроводности. М., Гостехтеориздат, 1952.

Ннститут энергетики

Академии наук Эстонской ССР
Поступила в редакцию

14. VII 1960 


\title{
KUKERSIIDI TEMPERATUURIJUHTIVUSEST TEMA KUUMUTAMISE JA TERMILISE LAGUNEMISE PROTSESSIS
}

R. Valdek ja N. Lutskovskaja, tehniliste teaduste kandidaadid

\section{J. Eisen}

Resümee

Artiklis esitatud diktüoneemakilda ja pōlevkivi ning tema koksi temperatuurijuhtivust uuriti keskkonnas, kus temperatuur muutus pidevalt (lineaarselt). Katseteks võeti nn. piiramatu silindri kujulised proovikehad, millede temperatuurijuhtivuskoefitsient arvutati valemi järgi:

$a=\frac{b R^{2}}{\Gamma\left(t_{\mathrm{n}}-t_{\mathrm{u}}\right)}$, kus $b-$ keskkonna kuumenemtse kiirus; $R-$ silindri raadius; $\Gamma-$ kons-

tant, piramatu silindri jaoks $\Gamma=4 ; t_{\mathrm{n}}-t_{\mathrm{u}}-$ uuritava keha välispinna ja tsentri temperatuuri vahe.

Esitatakse andmed põlevkivi ja tema koksi proovikehade temperatuurijuhtivuskoefitsiendi muutuste kohta, mis toimuvad paralleelselt kihtidele, kuumutamise tingimustes (s. o. termilise lagunemise protsessis).

Uleminekul põlevkivist koksiks suureneb temperatuurijuhtivus järsult, eriti kukersiidi puhul, mille keemiline koostis muutub järsumalt kui diktüoneemakildal.

Uurimistulemused näitavad, et kukersiidi ja tema kokside temperatuurijuhtivus väheneb proovikehade poorsuse suurenemisega, kuid see on kehtiv ainult keemiliselt koostiselt lähedaste proovikehade puhul.

Eesti NSV Teaduste Akadeemia

Energeetika Instituut

Saabus toimetusse

14. VII 1960

\section{ON THE THERMOCONDUCTIVITY OF KUKERSITE IN THE PROCESS OF HEATING AND THERMAL DECOMPOSITION}

\author{
R. Valdek, N. Lutskovskaya, J. Eisen
}

\section{Summary}

The article describes the study of the thermoconductivity of dictyonema shale and oil shale and its coke in conditions where the temperature was under a permanent (lineary) change. At the experiments samples having the shape of a so-called uncircumscribed cylinder were taken, whose temperature conductivity coefficient was computed according to the formula

$a=\frac{b R^{2}}{\Gamma\left(t_{\mathrm{n}}-t_{\mathrm{u}}\right)}, b-$ representing the velocity of heating; $K-$ the radius of the cylinder; $\Gamma$ - the constant for the uncircumscribed cylinder $=4 ; t_{\mathrm{n}}-t_{\mathrm{u}}-$ the difference in the temperatures of the surface and centre of the tested sample.

Data are presented on the changes of the temperature conductivity changes of oil shale and its coke, which are effected in parallel to the layers (i. e. in the process of thermal decomposition).

At the transition of oil shale to coke the temperature conductivity increases sharply, especially in case of kukersite, whose chemical composition changes more sharply than that of dictyonema shale. The results of the experiments showed that the temperature conductivity of kukersite and its cokes decreases with the increase of the porosity of samples, but this is valid only in case of samples of similar chemical composition.

Academy of Sciences of the Estonian S. S. R., Institute of Energetics
Received

July 14 th, 1960 